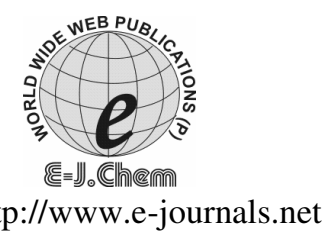

ISSN: 0973-4945; CODEN ECJHAO
E-Journal of Chemistry
$2010, \mathbf{7}(\mathbf{2}), 531-539$

\title{
Preparation and Characterization of Activated Carbon Monoliths with Potential Application as Phenol Adsorbents
}

\author{
DIANA PAOLA VARGAS-DELGADILLO, LILIANA GIRALDO, \\ and JUAN CARLOS MORENO-PIRAJÁN**
}

Faculty of Sciences, Department of Chemistry, Universidad Nacional de Colombia.

*Faculty of Sciences, Department of Chemistry, Research Group of Porous Solids and Applied Calorimetry, Universidad de Los Andes, Colombia.

jumoreno@uniandes.edu.co

Received 2 February 2009; Accepted 6 June 2009

\begin{abstract}
A series of different activated carbons of both honeycomb and disc type were prepared by chemical activation of coconut shells with zinc chloride at different concentrations, without the use of a binder. The structures were characterized by $\mathrm{N}_{2}$ adsorption at $77 \mathrm{~K}$ and scanning electron microscopy (SEM), and also some samples were characterized by immersion calorimetry in benzene. These were subsequently used in the adsorption of phenol in aqueous solution. The experimental results indicat that activation with zinc chloride produced a large development of microporosity with a micropore volume of 0.38 to $0.79 \mathrm{~cm}^{3} \mathrm{~g}^{-1}$, BET area between 725 and $1523 \mathrm{~m}^{2} \mathrm{~g}^{-1}$ and the capacity to adsorb phenol. In addition, the BET and Langmuir models were applied to isotherm data.
\end{abstract}

Keywords: Chemical activation, honeycomb, Coconut shells, Carbon monoliths, Phenol adsorption.

\section{Introduction}

In recent decades, alternative technologies have been developed for reducing pollution in gaseous and liquid phases. Solutions such as the use of granular activated carbon (GAC), powder activated carbon (PAC), fibers carbon (FAC) and activated carbon monoliths (ACM), among others, have been widely implemented due to the increasing demand and great versatility of these materials. The characteristics of ACM have resulted in it being termed a "new material" and it has been used in a wide range of areas such as the operation of air conditioning systems, in supporting the catalytic and the chemical industry in the removal of compounds such as benzene, acetone, dichloromethane, hexane and acrylonitrile, 
among others ${ }^{1,2}$. The porous structure of the ACM is made up mostly by micropores, whereas other activated carbons have a complex structure consisting of micropores, mesopores and macropores. The word "monolith" means "one stone" and refers to compact structures such as monoliths of the disc and honeycomb types. The latter are unit structures crossed lengthwise by parallel canals ${ }^{2}$ and constitute a new concept in the design of catalysts and adsorbents. This has allowed major innovations to emerge in recent decades. These new structures offer low values drop to the passage of gases, facilitating the uniform flow of the same, excellent mechanical properties, a large surface area per unit weight or volume and they also behave like most adiabatic systems and reduce the constraints generated by the phenomenon of internal diffusion $^{2}$. When comparing the properties of monolithic catalysts with those of catalysts with more conventional forms (cylinders, spheres, rings, etc.), it was found that the compact structure not only facilitates management but allows freedom of orientation in the reactor and significantly reduces the problems of the restriction granular catalysts ${ }^{3}$.

These structures can be synthesized from materials such as $\gamma$-alumina, silica, titanium oxide, cordierite and lignocellulosic materials, among others. The latter generate monoliths that can potentially be used as direct adsorbents or catalytic supports, and studies have increased to establish appropriate conditions for synthesis. The aim of this study was to assess the preparation of activated carbon monoliths (ACM) of honeycomb and disc types from coconut shells, through chemical activation with zinc chloride $\left(\mathrm{ZnCl}_{2}\right)$ and formation by pressing without the use of a binder ${ }^{4}$. The structures were characterized by determining $\mathrm{N}_{2}$ adsorption isotherms at $77 \mathrm{~K}$, scanning electron microscopy and immersion calorimetry in benzene. Additional tests were performed with the ACM to determine their phenol adsorption capacity in aqueous solutions.

\section{Experimental}

Figure 1 represents the ACM synthesis process.

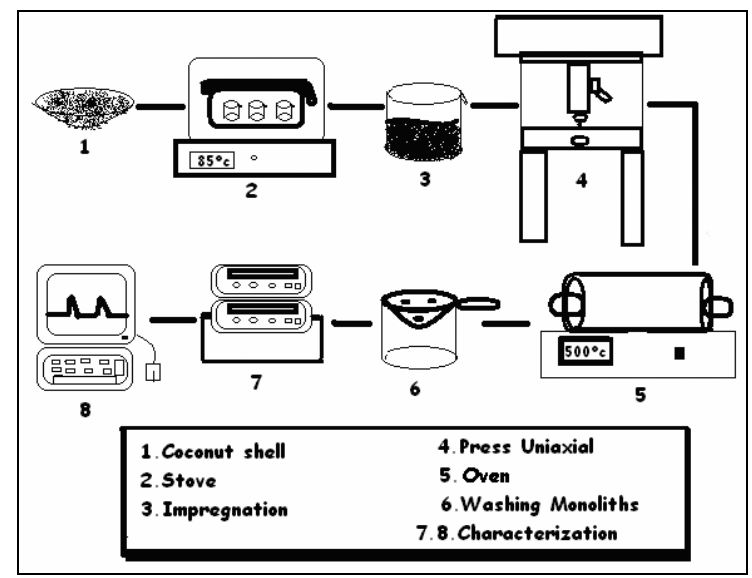

Figure 1. The monolith synthesis process.

\section{Preparation and characterization of the precursor material}

The coconut shell was ground and sieved for the synthesis process using a particle size of $38 \mu \mathrm{M}$. In order to establish its behavior under different temperatures, the raw material was impregnated and subjected to thermogravimetric analysis (TGA) $)^{5}$. The sample analysis was undertaken using NETZSCH STA 409 PC / PG, and for this purpose $94.70 \mathrm{mg}$ of coconut shell was used, with a flow of $\mathrm{N}_{2} 1 \mathrm{~mL} \mathrm{~min}^{-1}$ and a temperature range between $303 \mathrm{~K}$ and $1373 \mathrm{~K}$. 


\section{Activated carbon disc and honeycomb synthesis}

The precursor was impregnated with a desiccating agent, in this case zinc chloride, at $1 \mathrm{~g}$ of precursor for $2 \mathrm{~mL}$ of solution, for $7 \mathrm{~h}$ at $358 \mathrm{~K}$, followed by drying at $383 \mathrm{~K}$ for about $2 \mathrm{~h}$. Then carry a press axial, which was formed by pressing at $423 \mathrm{~K}$ at a pressure of $4500 \mathrm{psi}$. These structures were then carbonized in an oven at a temperature of $773 \mathrm{~K}$, a $\mathrm{N}_{2}$ flow of $85 \mathrm{~mL} \mathrm{~min} \mathrm{~m}^{-1}$ and a heating rate of $274 \mathrm{~K} \mathrm{~min}^{-1}$ for $2 \mathrm{~h}$. Finally, they were washed with $0.1 \mathrm{M}$ hydrochloric acid and distilled water until a neutral $\mathrm{pH}$ was reached, to eliminate the remnants of the chemical agents used during impregnation ${ }^{6}$.

Different $\mathrm{ZnCl}_{2}$ concentrations $(20 \%, 32 \%$, 48\%) were used to prepare the monolith series, symbolized by the letters MFD1 for disks and MFH2 for honeycombs, followed in each case by the concentration used for each series (MFD120, MFD132, MFD148, MFH220, MFH232, MFH248). Other conditions were maintained as constant. The relative impregnation values for each set are $0.19,0.30$ and 0.46 respectively.

\section{Characterization of the structures}

All activated carbon monoliths were characterized by physical adsorption of $\mathrm{N}_{2}$ to $77 \mathrm{~K}$ using the Quantachrome, Autosorb 3-B. The microporous volume was estimated by applying the Dubinin-Radushkevich equation and the surface area was obtained using the BET method. Some samples were characterized by immersion calorimetry in benzene $(0.37 \mathrm{~nm})$, using Calvet-type equipment ${ }^{7}$ and scanning electron microscopy (SEM).

\section{Determination of the phenol adsorption capacity from aqueous solutions}

Calibration curves of absorbance, depending on the phenol concentration in the aqueous solutions, at a wavelength of $269 \mathrm{~nm}$ were determined. To determine the phenol adsorption of the activated carbon monoliths, $500 \mathrm{mg}$ of solids were placed in glass bottles with $50 \mathrm{~mL}$ of a phenol aqueous solution (of 500 and $1500 \mathrm{mgL}^{-1}$ ) and the solutions were adjusted to $\mathrm{pH} 7$. The samples were shaken mechanically and kept at a temperature of $298 \mathrm{~K}$, for a period of approximately $48 \mathrm{~h}$. The residual phenol concentration in the solutions after adsorption was determined by spectrophotometric UV-Vis, Milton Roy Co. Spectronic Genesys SN.

\section{Results and Discussion}

Thermogravimetric analysis (TGA)

Figure 2 represents the analysis undertaken for raw coconut shell and coconut shell impregnated with $20 \%, 32 \%$ and $48 \%$ of $\mathrm{ZnCl}_{2}$. From the TGA obtained for coconut shell raw it can be seen that between $323 \mathrm{~K}$ and $453 \mathrm{~K}$ there was a loss of $10.27 \%$ of the initial mass in relation to the elimination of moisture from the sample in addition to moisture also removed by volatile compounds, which are carried by the steam flow that comes from biomass during the evaporation process. This is consistent with the behavior of the DTA which indicates an endothermic process of water evaporation. At temperatures above $493 \mathrm{~K}$, the thermogravimetric registration slope changed significantly, indicating the beginning of the carbonization process caused by the vaporization of the volatile compounds. At a temperature of $574 \mathrm{~K}$, a $22.63 \%$ loss in mass occurred. In the temperature range of $493 \mathrm{~K}$ and $603 \mathrm{~K}$, an increasing loss of the materials was observed due to components that were torn away from the amorphous structure more easily due to the effects of temperature. Between $603 \mathrm{~K}$ and $723 \mathrm{~K}$, the maximum values of mass loss occurred, obtaining a solid residue virtually without volatile compounds, but still with an incomplete carbonization degree inside the samples. In a subsequent temperature interval higher than $673 \mathrm{~K}$, another change occurs on the slopes of the 
thermogravimetric records: temperatures in the range of $574 \mathrm{~K}$ to $773 \mathrm{~K}$ produce the main mass loss of $66.56 \%$ which is a result of the cellulose thermal degradation that occurs in two stages. First, there is a downsizing of the cellulose chain due to the severance of links from the generation of free radicals, carboxylic groups and carbonyls, as well as the formation of carbon, while the second stage includes cellulose depolymerization due to breakage of glucoside units and the formation of levoglucosan. Decomposition above $683 \mathrm{~K}$ is attributed to the degradation of cellulose and lignin, the main components of lignocellulosic materials ${ }^{8}$ and that coincides with the peak of the maximum zone of heat flow. Weight loss with respect to the initial mass continued, but this time at a very high temperature until soft. Between $773 \mathrm{~K}$ and $1073 \mathrm{~K}$ there was a loss of over $70.86 \%$ and in the range of $1073 \mathrm{~K}$ to $1099 \mathrm{~K}$ the remaining mass was $28.75 \%$, which indicates a loss of just $1.33 \%$ over a considerable range of $572 \mathrm{~K}$. The fixed carbon content, in the waste product that was carbonized, increased with rising temperatures, becoming a solid porous mass. The observed correspondence with the thermogravimetric registration slope (Figure 2) illustrates that in the intervals between $493 \mathrm{~K}$ and $723 \mathrm{~K}$, approximately $66 \%$ of the mass loss occurred. At pyrolysis temperatures above $723 \mathrm{~K}$ will arise charred of appropriate conditions for the subsequent adsorbents synthesis ${ }^{9}$, recommending the use of a low heating rate to avoid drastic morphological damage during the pyrolysis process and subsequent activation.

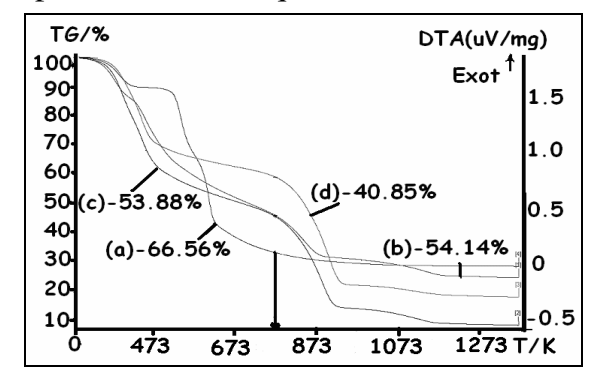

Figure 2. Thermogravimetric analysis of raw coconut shell and with impregnation of $\mathrm{ZnCl}_{2}$ (a) raw (b) $20 \% \mathrm{ZnCl}_{2}$ (c) $32 \% \mathrm{ZnCl}_{2}$ and (d) $48 \% \mathrm{ZnCl}_{2}$.

Following the TGA, the coconut shell was impregnated with the aforementioned concentrations and analysis was focused on the temperature of $773 \mathrm{~K}$. It was noted that in general, at greater concentrations of impregnating agent, there was a minor loss of mass and therefore more structure available for the carbonization process. This was illustrated by the mass loss rate at this point (raw - 66.56\% [20\%] - 54.14\% [32\%] - 53.88\% [48\%] - 40.85\%) and at the same time, the process of dehydration increased sharply with the impregnation and a minor release of volatile materials under increasing concentration of $\mathrm{ZnCl}_{2}$ occurred. Therefore more tars are available on the surface to set the carbon and improve the performance of the process ${ }^{10}$, which was observed by the slope of each thermogram. A temperature of $773 \mathrm{~K}$ shows a mass loss of approximately $50 \%$, which makes it possible to obtain a porous solid with good characteristics.

\section{The characteristics of the structures}

Figure 3 shows that isotherms obtained for the honeycomb and discs types illustrate the synthesis of microporous structures with a good surface area and micropore volume. The isotherms are type I solids with large micropores, which have surface areas between 725 and $1523 \mathrm{~m}^{2} \mathrm{~g}^{-1}$ and a microporous volume between 0.39 and $0.79 \mathrm{~cm}^{3} \mathrm{~g}^{-1}$. These results are satisfactory, taking into account that under similar synthesis conditions surface areas between 500 and $2000 \mathrm{~m}^{2} \mathrm{~g}^{-1}$ have been obtained ${ }^{6}$, together with a microporous volume of between $0.2-1 \mathrm{~cm}^{3} \mathrm{~g}^{-1}$. 


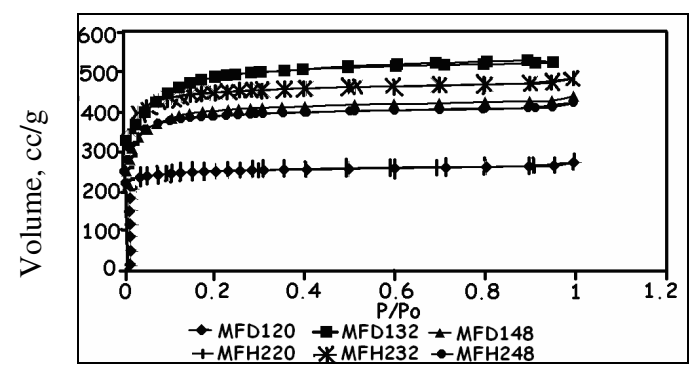

Figure 3. $\mathrm{N}_{2}$ adsorption isotherms to $77 \mathrm{~K}$ of honeycombs and disc at different concentrations of $\mathrm{ZnCl}_{2}$.

Table 1 shows that yield of carbonization increase with increase of concentrations of the impregnating agent. This fact is agree with the results obtained of TGA for different samples, since a major concentration of impregnation agent more residual mass available in the carbonization. The heating process during pressing reduced the loss of volatile matter and increases the resistance of porous solids synthesized. Finally, during heat treatment the impregnating agent acts as a drying agent that favor the release of hydrogen and oxygen into the interior in the form of $\mathrm{H}_{2} \mathrm{O}, \mathrm{COx}$ or hydrocarbons

Table 1. Characteristics of the synthesized ACM.

\begin{tabular}{ccccc}
\hline $\begin{array}{c}\text { Series } \\
\text { Monoliths }\end{array}$ & $\begin{array}{c}\text { Relationship of } \\
\text { impregnation }\end{array}$ & $\begin{array}{c}\text { Microporous } \\
\text { Volume DR cm }\end{array} / \mathrm{g}$ & $\begin{array}{c}\text { Área } \\
\mathrm{BET} \mathrm{m}^{2} / \mathrm{g}\end{array}$ & Yield \\
\hline MFH220 & 0,19 & 0,39 & 726 & $45,94 \%$ \\
MFH232 & 0,30 & 0,72 & 1315 & $50,83 \%$ \\
MFH248 & 0,46 & 0,62 & 1170 & $53,71 \%$ \\
MFD120 & 0,19 & 0,45 & 821 & $35,09 \%$ \\
MFD132 & 0,30 & 0,79 & 1523 & $45,05 \%$ \\
MFD148 & 0,46 & 0,65 & 1206 & $51,93 \%$ \\
\hline
\end{tabular}

Table 2. Characteristics of the synthesized ACM (Immersion enthalpy and adsorption of phenol).

\begin{tabular}{|c|c|c|c|c|}
\hline Series & $-\Delta$ Hinm & \multirow{8}{*}{ 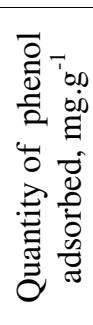 } & 1500 & 500 \\
\hline Monoliths & $\mathrm{J} \mathrm{g}^{-1}$ & & ppm & ppm \\
\hline MFD120 & 30.71 & & 24.04 & 7.38 \\
\hline MFD & 63 & & 78.05 & 32.41 \\
\hline MFD & 36.95 & & 55.52 & 22.32 \\
\hline MFH220 & 25.23 & & 39.69 & 20.09 \\
\hline MFH232 & 38.16 & & 108.61 & 35.91 \\
\hline MFH248 & 35.19 & & 93.61 & 31.33 \\
\hline
\end{tabular}

This impregnation agent penetrates into the interior of the particles producing a partial fragmentation of cellulose and other biopolymers of plant structures such as lignin and hemicelluloses. The reactions that followed were dehydration and condensation and enabled more aromatic compounds to be produced with the appearance of tar, which remained on the particle surface, impregnated and acted as a binder ${ }^{11}$. Due to this it was not necessary to use any material that agglomerates the precursor particles, so the porosity was not affected by the presence of the binder after carbonization. As a result of precursor impregnation with $\mathrm{ZnCl}_{2}$, the mass deformed with the pressure, allowing the reduction of space between particles. This data was obtained from the $\mathrm{N}_{2}$ adsorption isotherms used in the application of two models of gas adsorption, BET and Langmuir. Figures $4 \& 5$ show a linear trend of the data revealed by good correlation coefficients of around 0.9995-0.9998. 


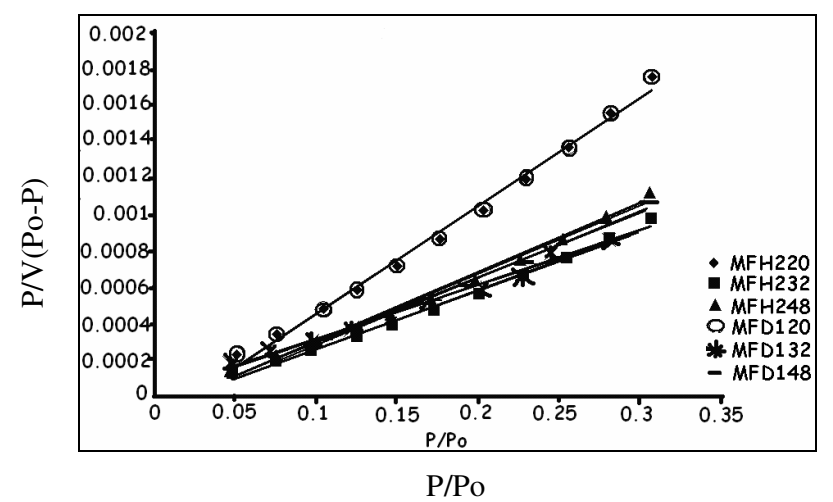

Figure 4. Representation of the BET model for the series of synthesized monoliths.

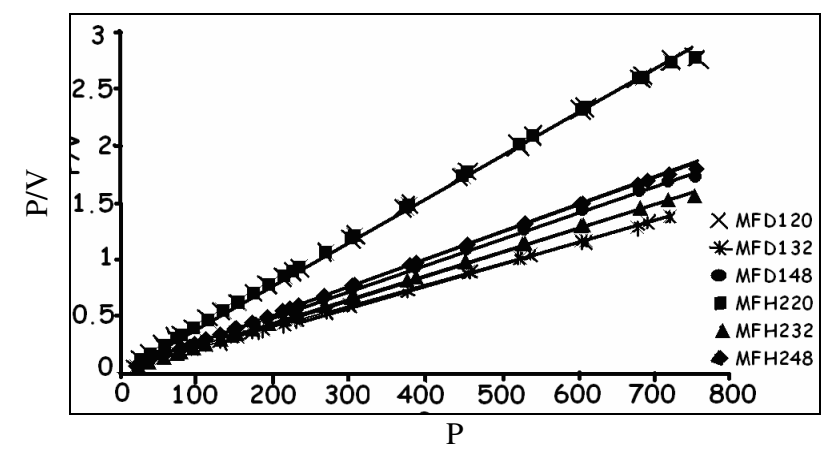

Figure 5. Representation of the Langmuir model for the series of synthesized monoliths.

The characteristic data of the BET and Langmuir models is shown in Table 3. When comparing the values of $\mathrm{Vm}$ a marked trend can be observed between the two models. The $\mathrm{Vm}$ values obtained from the BET model are lower than those calculated by the Langmuir model, and are independent of the considered adsorption ${ }^{12,13}$. But in both cases $V m$ increases with the surface area of the ACM. In Figure 5, it is shown that the Langmuir model is sensitive to variations in the carbon porosity, thus for carbons with a greater porosity (MFD132, MFH232) the slope is less step than for carbons with a lower porosity (MFD120, MFH220) although activated carbons fit straight model to Langmuir representations, the point in coordinate $Y$ was both, displaced to minor pressure, when the microporosity of carbon is broader and the slope of the straight stretch at higher pressures, decreases in thesame direction ${ }^{14}$. Also it can be noted that parameter $\mathrm{K}$, which is between 0.068 and 0.100 for all samples, is sensitive to changes in carbon microporosity, being so much while more microporoses is the carbon such that the series MFH232, which has a pore volume of 0.79 , presents the greatest $\mathrm{K}$ value of 0.1 .

Two constants characterize the equation isotherm of BET: $V m$, which is the adsorption capacity in the monolayer and $\mathrm{C}$, constant energy, which is a parameter associated with the difference between energy adsorption of the molecules in the first layer and the other remaining layers. Table 3 illustrates the change in parameter $\mathrm{C}$ in the series of synthesized monoliths of a range between 42 and 331, being higher in samples MFD132 and MFH32. This coincides with the main phenol adsorption capacity of these samples in comparison to the other samples and is a consistent behavior since parameter $\mathrm{C}$ gives an idea of the molecules residence time on the surface. When $\mathrm{C}$ is large, the residence time of adsorbate is longer, which indicates a high potential for interaction on the surface and consequently a significant heterogeneity energetic ${ }^{14}$. 
Table 3. Characteristics of the synthesized ACM (Models BET and Langmuir).

\begin{tabular}{|c|c|c|c|c|c|c|}
\hline $\begin{array}{c}\text { Series } \\
\text { Monoliths }\end{array}$ & \multirow{7}{*}{ 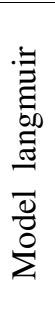 } & $\begin{array}{l}\mathrm{Vm}, \\
\mathrm{cm}^{3} \cdot \mathrm{g}^{-1}\end{array}$ & K & \multirow{7}{*}{$\begin{array}{l}\bar{D} \\
\bar{d} \\
\bar{d} \\
\sum\end{array}$} & $\begin{array}{l}\mathrm{Vm}, \\
\mathrm{cm}^{3} \cdot \mathrm{g}^{-1}\end{array}$ & C \\
\hline MFD120 & & 270.27 & 0.096 & & 188.68 & 53 \\
\hline MFD132 & & 526.31 & 0.068 & & 349.65 & 146 \\
\hline MFD148 & & 434.78 & 0.082 & & 277.01 & 42 \\
\hline MFH220 & & 270.27 & 0.096 & & 166.67 & 60 \\
\hline MFH232 & & 476.19 & 0.100 & & 302.11 & 331 \\
\hline MFH248 & & 416.66 & 0.094 & & 268.82 & 49 \\
\hline
\end{tabular}

The immersion enthalpy is indicative of the interaction between solids and the immersion liquid, which in this work was the phenol aqueous solution. The value of this property corresponds to the total quantity of heat generated in the solute adsorption process, and therefore also implies interaction with the solvent. In Table 2, showing the immersion enthalpy values of the ACM in benzene, the immersion enthalpy values obtained for the different sets of discs and honeycombs show that a main area BET greater immersion enthalpy (Figure 6) being this agree and that there is greater surface area ready to interact with the adsorbate. The correlation coefficients show that the data are consistent with the linearity.

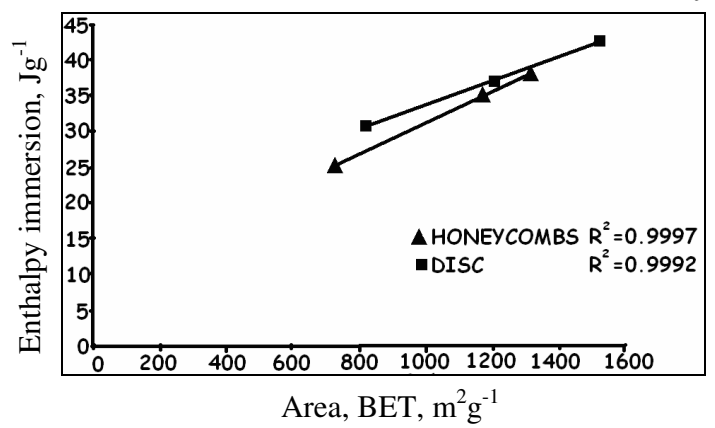

Figure 6. Immersion enthalpy of the monoliths honeycomb and disc in benzene in the BET area.

The ACM were tested as potential adsorbents of phenols in an aqueous phase and this data is shown in Table 2. It can be seen that the monoliths of the honeycomb type series have a greater capacity for phenol retention compared to the disc type series. This is due to the fact that the honeycomb channels facilitate adsorption of this molecule since the problems of transport in solution are reduced. Figure 7 shows that when the surface area is larger, phenol adsorption increases. In addition there is a linear behavior to the data.

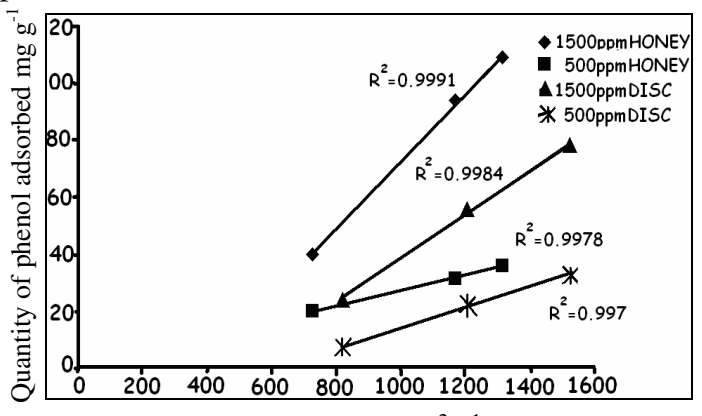

Area BET, $\mathrm{m}^{2} \mathrm{~g}^{-1}$

Figure 7. Phenol adsorption quantity as a function of the monolith area surface. 


\section{Scanning electron microscopy (SEM)}

Microphotographs of the selected samples are shown in Figure 8. In both cases surface features and regions of internal and external structures can be seen, as can the empty spaces between the particles. They are comparable with those obtained in other similar works ${ }^{10,15,16}$ Figure $8 \mathrm{a}$ shows the drilling of the honeycombs and $8 \mathrm{~b}$ the dimensions of small points of the structure of the discs.
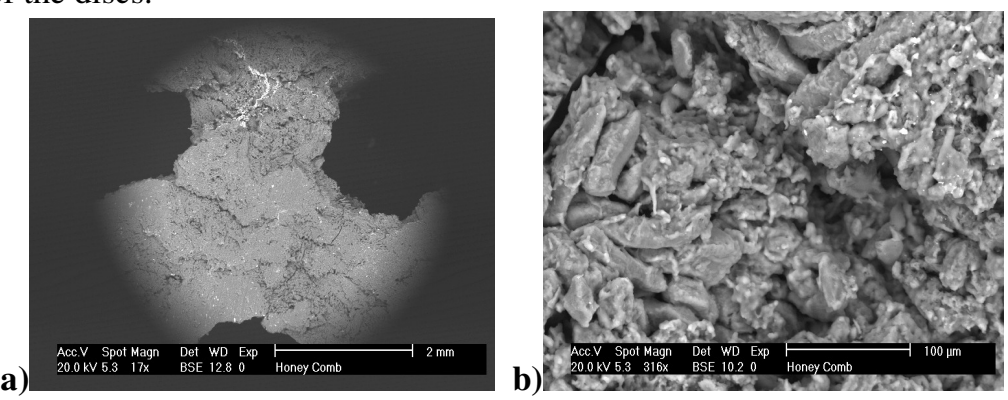

Figure 8. Microphotographs of SEM discs and honeycombs at $20 \%$.

\section{Conclusions}

The use of $\mathrm{ZnCl}_{2}$ as an impregnation agent is appropriate for activated carbon monolith synthesis. Using coconut shell as a precursor material resulted in structures that possessed good mechanical and textural properties. These properties were achieved due to the heating that takes place in the various processes of the preparation and the resulting structures could be used for the adsorption of different compounds.

The temperature formed by pressing of the precursor particles is key for the synthesis of the structures. The optimum temperature was found to be $423 \mathrm{~K}$ since at this temperature the loss of volatile matter is low, which helps with the resistance. Six samples of activated carbon monoliths (discs and honeycombs) were prepared, achieving BET areas between 702 and $1523 \mathrm{~m}^{2} \mathrm{~g}^{-1}$, together with a microporous volume of between 0.38 and $0.79 \mathrm{~cm}^{3} \mathrm{~g}^{-1}$. The most desirable characteristics were obtained in samples MFD132 (discs) and MFH232 (honeycombs), and were obtained under the same conditions, the shape of the structures being the only variation. Evaluation of the influence of the relationship between impregnation in an area and microporous volume found a maximum value in developing the area and micropores for a relation of $0.3 \mathrm{~g}$ of $\mathrm{Zn}$ per $\mathrm{g}$ of coconut. An increase in the yield from the carbonization process with a larger relative impregnation was also observed and attributed to a greater residual mass available for carbonization due to a larger amount of volatile matter retained, as illustrated by thermogravimetric analysis.

On comparison of the BET and Langmuir models, it was found that the Vm values were higher for the Langmuir model in all cases. Also, the immersion calorimetry in benzene showed a directly proportional relationship between BET area and enthalpy as a parameter characterization that demonstrates the solid-liquid interactions.

Finally, it was observed that the synthesized activated carbon monoliths are materials with potential application to the adsorption of phenol from aqueous solutions. Quantities of phenol adsorbed ranged between 7.38 and $35.91 \mathrm{mg} \cdot \mathrm{g}^{-1}$ for phenol solutions of $500 \mathrm{mgL}^{-1}$ and between 24.02 and $108.61 \mathrm{mg} . \mathrm{g}^{-1}$ for phenol solutions of $1500 \mathrm{mgL}^{-1}$, despite that the honeycombs retain a main quantity of phenol that discs similar areas, both were found to reduce the phenol concentration in a solution 


\section{Acknowledgments}

The authors wish to thank the Master Agreement established between the "Universidad de los Andes" and the "Universidad Nacional de Colombia" and the Memorandum of Understanding entered into by the Departments of Chemistry of both universities.

\section{References}

1. Mohan D, Singh K P and Vinod K, J Hazard Mater., 2008, 152, 1045.

2. Yates M, Blanco J, Avila P and Martin M P, Microporous and Mesoporous Materials, 2000, 37, 201.

3. Peng Y L, Tao T and Williams J L, Carbon 99, $24^{\text {th }}$ Biennial Conference on Carbon, Charlotte, 1999, 450-451.

4. Nakagawa Y, Molina-Sabio M and Rodriguez-Reinoso F, Microporous and Mesoporous Materials, 2007, 103, 29.

5. Medina-Álvarez B F, Villegas-Aguilar P J and De Las Posas del Río C E, Centro de Estudio de Termo energética Azucarera, Facultad de Ingeniería Mecánica, Universidad Central de Las Villas. La Plata, Argentina. 2003.

6. Rodríguez Reinoso F, Almansa F C. and Molina-Sabio M, Universidad de Alicante. Patente: 2165784, 2003.

7. González M T, Sepúlveda-Escribano A, Molina-Sabio M and Rodríguez-Reinoso F, Langmuir, 1995, 11, 2151.

8. Modorsky S L and Krieger R E, Publicado Co Melbourne, USA, 1975, 238-261.

9. Agencia Iberoamericana de cooperación para el desarrollo, Libro contenedor de una compilación de trabajos de de la Red Temática V. F, Red Iberoamericana de Adsorbentes para la Protección Ambiental. Editado por Francisco Rodríguez Reinoso (ISBN: 84 - 96023 - 37 - 0), Noviembre, 2005.

.10. Almansa C, Molina-Sabio M and Rodriguez-Reinoso F, Microporous and Mesoporous Materials, 2004, 76, 185.

11. Cartula F, Molina-Sabio M and Rodriguez-Reinoso F, Carbon, 2003, 4, 2113.

12. Linares-Solano A, Lopez Gonzalez J D, Molina Sabio M, and Rodriguez- Reinoso F, J Chem Tech Biotechnol., 1980, 30, 65.

13. Lopez-Gonzalez J D, Martinez-Vilchez F and Rodríguez-Reinoso F, Carbon, 1980, 18, 413.

14. Martín-Martinez J M, Adsorción física de gases y vapores por carbones. Universidad de Alicante. España, 1990, capítulo 3.

15. Lozano-Castelló D, Cazorla-Amorós D, Linares-Solano A and Quinn D F, Carbon, 2002, 40, 2817.

16. Ubago-Pérez R, Carrasco-Martín F, Fairén-Jiménez D and Moreno-Castilla C, Microporous and Mesoporous Materials, 2006, 92, 64. 


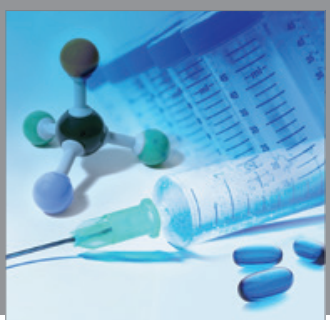

International Journal of

Medicinal Chemistry

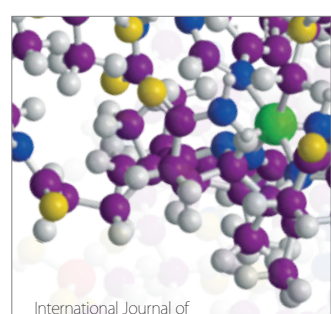

Carbohydrate Chemistry

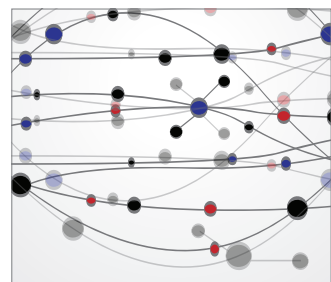

The Scientific World Journal
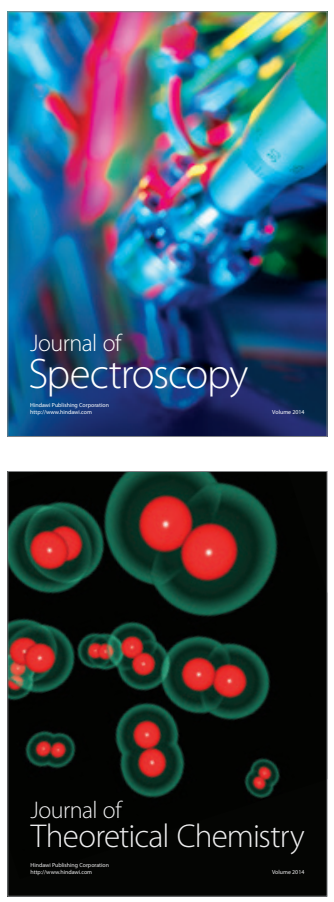
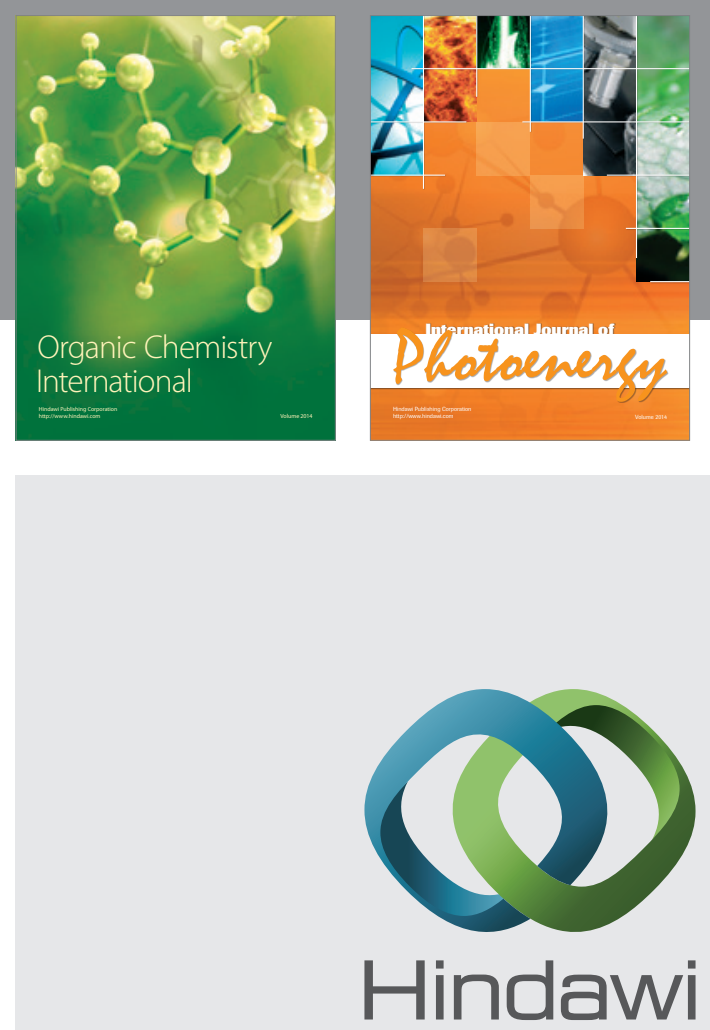

Submit your manuscripts at

http://www.hindawi.com
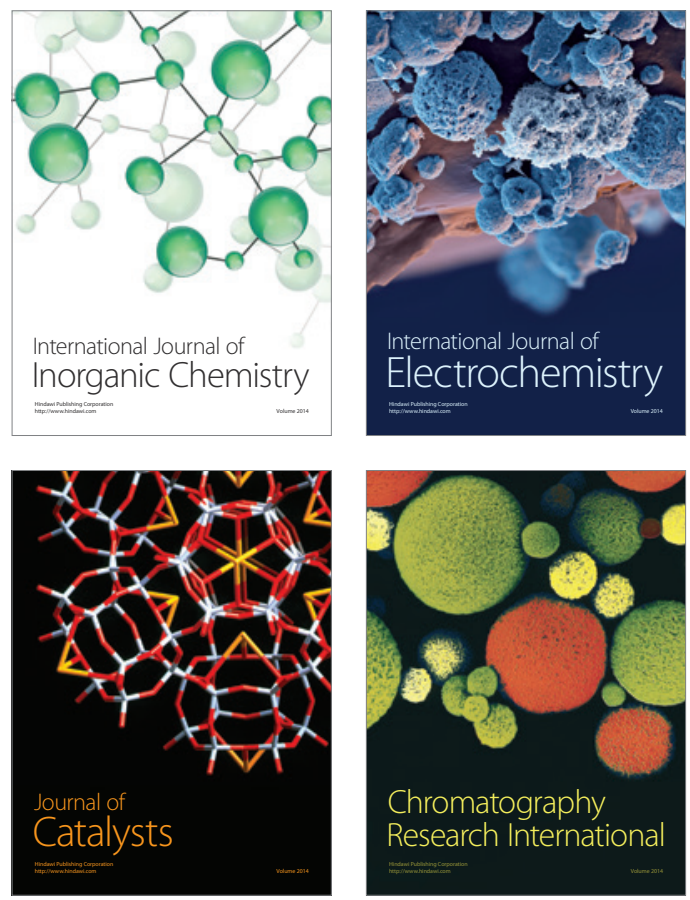
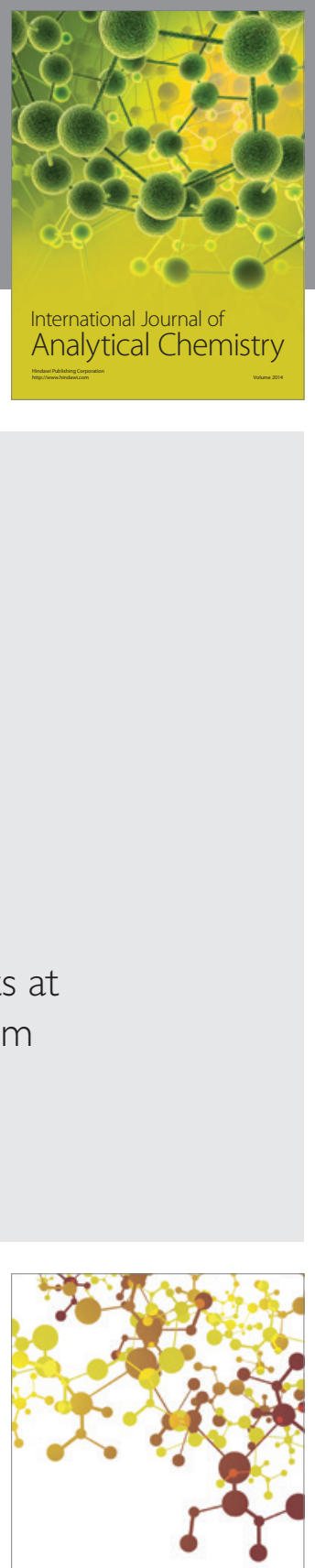

Journal of

Applied Chemistry
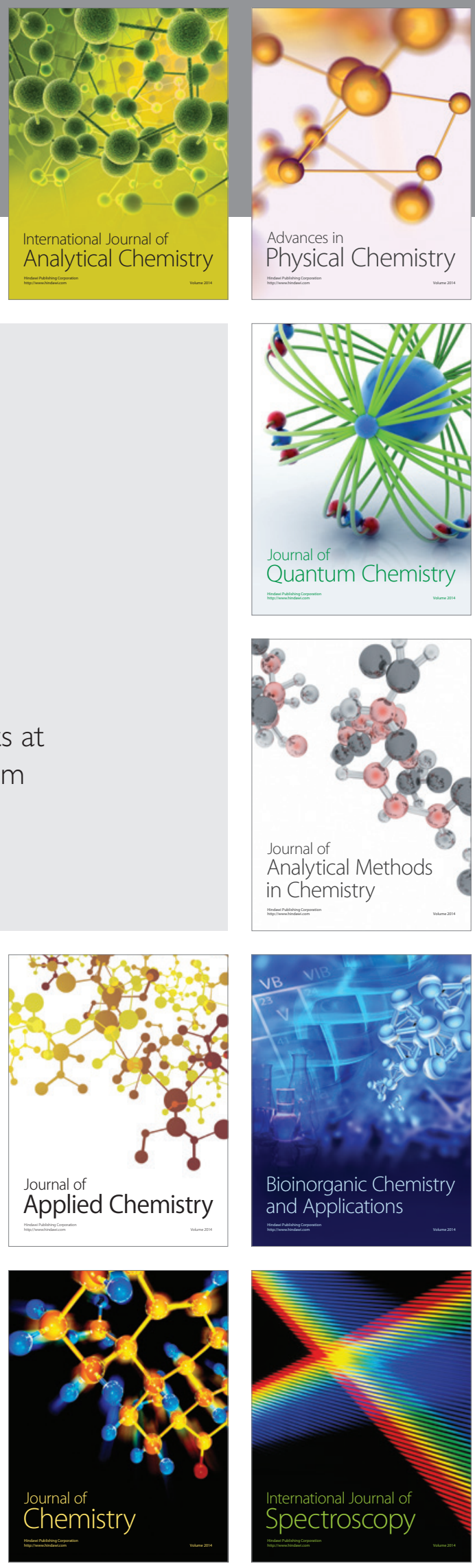